\title{
LXII. Memoir on the stones said to have fallen from the heavens. Read in the French National Institute
}

\section{Vauquelin}

To cite this article: C. Vauquelin (1803) LXII. Memoir on the stones said to have fallen from the heavens. Read in the French National Institute , Philosophical Magazine Series 1, 15:60, 346-354, DOI: $10.1080 / 14786440308676286$

To link to this article: http://dx.doi.org/10.1080/14786440308676286

曲 Published online: 18 May 2009.

Submit your article to this journal $\pi$

Џll Article views: 2

Q View related articles $\sqsubset$ 


\section{[ 346 ]}

LXII. Memoir on the Stones faid to bave fallen from the Heavens. Read in the Frencb National Infiitute by C. Vavquelin *

W

fallen from the hedrens, and while philofophers, divided in opinion on this fubject, were forming hypothefes to explain the origin of them, each accordingr to his own manner, $\mathrm{Mr}$. Idward Howard, an able tnglifh chemift, was purfuing in filence the only route which conld lead to a folution of the problem. He collected fpecimens of flones which had fallen at different times, procured as much information as poffible refpecting them, compared the phyfical or exterior characters of thefe bodies; and cven did more, in fubjrcting them to chemical analyfis by means as ingenious as exact.

It refults from his refearches, that the ftones which fell in England, in Italy, in Germany, in the Eaft Indies, and in other places, have all fuch a perfest refemblance that it is almoft impoffible to diftinguifh them from each other; and what renders the fimilitude more perfect and more tiriking is, that they are compofed of the fame principles and nearly in the fame proportions.

Before the laft refults of the labour of Mr. Howard were known in France, I had employed myfelf on the lame object; and $I$ have the fatisfaction to find in his memoir, which has been fince printed, that they perfectly agree with thofe which I had obtained.

I thould have abftained from any public notice of an object which has been treated of in fo able a manner by the Englith chemift, if he himfelf had not induced me to do fo during his refidence at Paris; had not the ftones which I analyfed been from another country; and had not the intereft excited by the fubject rendered this repetition excufable.

It is therefore to gratify $\mathrm{Mr}$. Howard, to give, if poffible, more weight to his experiments, and to enable philofophers to place full confidence in them, rather than to offer any thing new, that I publifh this memoir. One of the ftones which I examined was tranfmitted to me by C. SaintAmans: it fell at Créon, in the parifh of Juliac, on the 24th of July 1790 , about nine in the evening. This ftone appeared in the air under the form of a fire-ball, which was vifible in almoft the whole of the fouth of France. A very

- From the Gournal des Mines, No.76. 
correct account was given of it at that time in the abbe Bertholon's Journal d'Hiftoire Naturelle, together with the proces-verbal of the municipality of the place, which confirmed the fall of this ftone.

Another ftone was given to me by M. Darcet junior: it fell at Barbotan, near Roquefort, in the month of July $178 \mathrm{~g}$. The brother of the late Darcet, curé in the neighboirhood, fent it to him, with the proces-verbal drawn up refpecting this extraordinary phænomenon. C. Lomet, who is known to feveral members of the Inftitute, was at Agen on the day when this kind of meteor appeared in the atmofphere. The following is the account which he gave me of it:

"It appeared as a very bright fire-ball, the light of which was as pure as that of the fun; it had the fize of a common air-balloon, and was long enongh vifible to throw the inhabitants of the country into the greateft confternation; after which it burft, and difappeared. A few days after, fome peafants brought ftones, which they faid were the refult of the fall of the meteor : but at that period they were laughed at. What they faid was confiklered as fables; and thofe to whom the ftones were offered, would not accept of them. The peafants would have now more reafon to laugh at philofophers."

The third kind of the fe ftone's is that brought from Benares in the Ealt Indies, which fell on the 19 th of December 1798 , exhibiting the very fame phænomena as were obferved under fimilar circumftances in other countries. It was given to me by C. De Drée and by C. Saint-Amans, who brought it from England.

All thefe ftones have a fimilar appearance, and one might readily believe that they had been detached from the fame mals. Their furface is blackilh. fmooth, and, as it were, varnithed by a cominencement of fufon. The infide is of a whitith gray colour marked with a greater or lefs number of brown fpots, or fpots of a darker gray colour than the reft of the mafs. Thofe, however, found at Benares, and in rorkfhire, are whiter in the interior part than thofe found in France. There are obferved in them white prrites, the fracture of which is very much lamellated; globules of metallic and ductile iron, fome of which weigh 46 Englifh grains; but this iron has a whiter colour, and a greater degrce of harduef, than common iron. The caule of this difference will be feen hereafter.

I withed to have been able to fubject to a feparate anaylfis each of the conftituent principles of thi fe Anes fenfible to the eye : but they are fo intimately mixed, that it was impoffible to feparate them exactly. By patience, however, 
I was able to obtain a fufficient quantity of the globules of iron and of pyrites to afcertain the nature of them.

A. A hundred parts of the funnes of Benares, pulverized in a mortar of hard ftone, and lified th:nugh a tine filk fieve to feparate the coarfeft particles of the iron which cannot be pulverifed, were treated with dilute nitric acid. During this operation there was difengaged a large pluantity of nitrous gas; the acid affumed a vellowilh grein coluur; the ftony powder became whitth, and, dividing itf:If, increafed confiderably in volume, fo that it refembled gelatimous filex. Sulphureous particles were obferved floating at the furface of the liquor.

B. When the action of the nitric acid ceafed, water was added to the mixture; the liguor being filtered, the undiffolved matter was wafhed, and after deliccation in the open air it weighed no more than 64 parts.

C. As the matter treated in this manner was fill llightly coloured, it was boiled with muriatic acid, which, as is well known, unites more eafily with oxidated iron: it affumed alto a greenith yellow colour, and the powder became much whiter. After this fecond operation the flone, when wathed and calcined in a platina crucible, weighed only 47 parts.

D. The nitric and muriatic aciels which had been fucceffively poured over the ftone as above mentioned were mixed together and then precipitater by ammonia, of which an excefs was added. Being heated for fome tirie, the liquor was filtered, and the precipitate was wathed and calcined: it had a brown colour, and weighed $3^{8}$ parts.

E. The ammoniacal liquor had a dight blue colour inclining to violet. Alkaline carbonates producel in it no precipitate; on the other hand, canftic alkalie formed a white precipitate very abundant, but the liquor lot none of its violet colour. This precipitate, when wafted and dried in the air, had a greenifh hade, and weighed 18 parts; calcination reduced it to 13 . This matter readily combined with fulphuric acid, and the refalt was a folution, which by fpontaneous evaporation prociuced prifmatic cryftals refembling in tafte and favour thofe of the fulphate of magnefia. It however had a night greenifh colour, and at the end of fome minutes produced in the month a metallic favour. To know whether the colour and favour of the fulphate of magnefia aroie from fome metallic fubfiances it was diffolved in water, and hydrofulphuret of ammonia being poured over it, a pretty voluminous black precipitate was produced. After wafhing and deficcation, however, it weighed only two parts. We fhall return hereafter to this matter.

F. The 
F. The ammoniacal liquor, from which the magnefia had been feparated by mans of caultic potalh, was mixed with a folution of fulphuarted hydrogen. By this mixture there was formed a very voluininous black precipitate, which when wahed and disul weighed feven parts. This part being united with the three parts obtained alfo by fulphate of magnefia, and kept at a red heat for fome minutes, exhaled the odour of fulphurcous acid, and acquired a very dark green colour inclining to brown: the whole then weighed fcarcely three parts.

A fmall quantity of this matter fufed with borax gave glafs of a hyacinth colour; put-into fulphuric acid diluted with water, it diffolved only in part, and a finall quantity which had a metallic appcarance refufed to combine with it; but the addition of a few drops of nitric acid, by oxidating it, favoured its folution : by fpontaneous evaporation it furnifhed elongated cryftals of a very beatiful green colour.

$B y$ the properties which this matter exhibited it is evident that it was nothing elfe but oxide of nickel; for it is the only one among the metals which poffefies the property of colouring borax of a byacinth red colour by fufion, of giving to ammonia a purplifh blue colour, of forming with fulphuric acid a prifmatic falt of a green colour, and of producing by its combination with acids and ammonia triple falts which are not precipitated by fixed alkalies.

An examination of the principles fucceffively obtained by the different means employed for analyfing the ftone of Benares, proves that it is compofed of filex, magnefia, and iron, a part of which appears to be uxidated, nickel and fulphur. Iron, nickel, and fulphur, according to every appearance, form a particular triple combination, which feems only to be interpofed between the earthy parts. I am, however, inclined to believe, that one part at leaft of thefe fubftances is really in combination with the earths; for at the moment when the ftone is attacked by the acids, the filex fhows itfelf in a ftate of very great divifon, and like a kind of jelly. The proportions in which thels matters are found in the fone of Benares are nearly as follows :

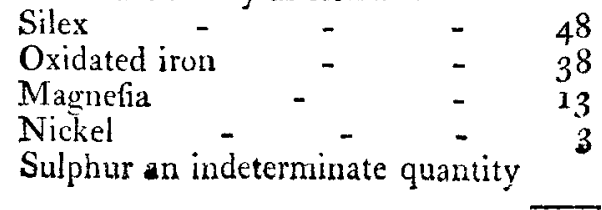


If we might fupnofe that the iron contained in this ftone exifts in the perfect metallic ftate, we might eafily find, by the increafe of weight which it acquires in confequence of oxygenation, the proportion of fulphur; but as it is certain that this metal is oxi lated in it in an unknown quantity, that of the f:alphur cann't be determined.

A hundred parts of this ftone, freed as far as could poffibly be done from ferruginous matters, were treated with muriatie acid diluted with a little water. The mixture produced immediately, with a ftrong effervefcence, a gas which had the odour of fulphurated hydrogen gas. The natter affumed the form of a gelatinous mafs, which feems to prove, as already faid, that the filex exifts in this ftone in a ftate of combination either with iron or with other fubftances.

When the effervefcence had fubfided, and the mixture had boiled for fome time, it was diluted with water and filtered. The liquor had a green colour analogous to that of muriate of iron, but a little darker. The refiduum when wafhed was white, and weighed 49 parts.

The muriatic folution and wathings being united together were precipitated by ammonia added in excefs, and were flirred for fome time with the precipitate.

It has been remarked, that oxidated iron, precipitated in this manner by ammonia, has a more intenfe colour than that of iron obtained under the fame circumftances. This iron, wafhed and dried, weighed 42 parts.

The liquor containing the fuperabundant ammonia in the precipitation of the iron had acquired a violet colour, which neither the heat nor the contact of the air made it lofe. Alkaline carbonates produced in it no alteration; on the other hand, fixed cauftic akalies formed in it a white precipitate pretty abundant, which when wafhed and calcined weighed twelve parts. This matter combined with fulphuric acid gave fulphate of magnefia, coloured green by a fmall quantity of nickel which the magnefia had carried down with it.

The liquor from which this earth had been feparated by potah had loft a part of its violet colour; it, however, ftill formed a black precipitate with fulphurated hydrogen. From what I had before obferved, I entertained no doubt that the fubftance which coloured the magnefia green, and was precipitated black by hodro-fulphuret of ammonia, was nickel. I therefore feparated, by means of this reagent, the portion which remained in folution and that which was mixed with the fulphate of magnefia: I united them, and having calcined them to feparate the fulphur, I obtained a green oxide, which weighed three parts and a half. 
The method employed to feparate the iron and the magnefia is founded on this circumftance, that a folution of that earth containing an excees of acid is not precipitated by ammonia, becaufe there is formed a triple falt, which cannot be decompofed by a fuperabundance of that alkali; but the acid muft be in fuch quantity that the falt refulting from its combination with the ammonid may be able to faturate the falt of magnefia exilting in the liquor. Care was taken to obferve this.

Alkaline carbonates produce no precipitation of the fubftances which enter into combination with the triple falt here mentioned, though it muft, however, be decompofed; but there is formed another kind, compofed of magnefia, carbonic acid, and ammonia, which remains in folution. But one thing I did not forefee was the fimultaneous precipitation of a portion of nickel and magnefia by the caultic potafh ; for, as $\mathrm{Mr}$. Howard remarked, this metal is found there in complex combination, the oxide of which ought to be diffolved by the ammonia in proportion as it becomes free: the precipitation of this metal muft be produced by its affinity for magnefia, at leaft this is what appears molt probable.

After thele two analyfes of the ftone of Benares, and the conformity of the refults which they furnithed, though effected by methods fomew hat different, there can be no doubt that it is really compofed of iron, filex, magnefia, nickel, and fulphur, as Mr. Howard announced.

Having therefore confirmed by thefe two means, and by others, which it is needlefs to mention, the refults given by the Englith chemift in regard to the cumpofition of the ftone of Benares, I fubjected to fimilar experiments two other kinds of ftone which fell in France, in order to afcertain whether they would furnith the fame principles of analyfis as their external characters feemed to announce.

To avoid a repetition of the details already given of the analytical methods employed, I thall only obferve, that the ftones which fell at Barbotan and Juliac, treated with fulphuric, nitric, muriatic, \&c. acids, exhibited in the feries of operations to which they were fubjected, and by the nature of the elements which they furnifhed, the mott perfect fimilarity to the preceding. It may therefore be confidered as fully proved, that the ftones faid to have fallen from the clouds in different countries are compofed of principles perfectly fimilar, and confequently that we muft have recourfe to a common caufe to explain their formation, and to fuppofe alfo a common fource from which nature derived the elements of them. I muft, however, acknowledge, that the fpecimens 
fpecimens of the ftones which have fallen in France are a little more charged with iron than thofe of other countries; but as this metal exifts in them, for the moft part, in diftinet globules which cannot be pulverized, they could have no influence on the refults of the analyfis, as the earthy part was fifted through a fine fieve.

All the ftones which have fallen to the earth, and particularly in France, contain, as I have already mentioned feveral times, globules of iron in a metallic ftace more or lefs diAtind, fome of which weigh from forty to fixty Englith grains. It appeared to me of importance to fubject this iron to fome analytical trials in order to afcertain the nature of their conftituent principles; but before I give the refults it mav be of utility that I hould firf give an account of their phyfical characters. Thefe globules are much whiter than common iron; their colour approaches that of tin ; their hardnefs is alfo greater, and confequently they are more difficult to be forged.

This metal diffolves eafily, and with effervefence, in all thofe acids which diffolve common iron; but inftead of giving pure hydrogen gas, it furnithes hydrogen gas very fentibly fulphurated. A part only of this hydrogen gas, indeed, is combined with the fulphur; for, having made it to pafs through water and cauftic alkalies, the greater part of-this fluid was not diffolved; and after having made the clifferent liquids here mentioned to pais in the fame manner, no fenfible figns of fulphur were given by reagents; but the water and the alkalies were manifeftly hydro. fulphurated, fince they then precipitated black the greater part of metallic folutions, and particularly lead. This fulphurated hydrogen gas exhibited to me a phænomenon which, as far as I know, has never been before obferved in its combination with waterI mean a very fpeedy decompofition which it experienced in a flafk perfectly clofed in which it had been prefersed for fome days. At the end of that time there were at the bottom of the water a great many fnall white laminx, and the water had no odour: it no longer precipitated folutions of lead. This gas then had experienced complete decompofition.

The folution of this iron in muriatic acid was precipitated by ammonia, of which a fuperabundance was added. The liquor when filtered had a colour inclining to purple; the oxide of iron, when wahed and calcined, was of a brown colour, and had fenfibly increafed in weight. The ammoniacal liquor when fubjected to evaporation depolited light traces of iron, but as long as there was ammonia in excefs 
it retained its blue colour, which, as foon as this free alkali was evaporated, was changed to a meadow green. The liquor conftantly preferved this colour, which fiill acquired greater intenfity until complete evaporation, and without forming any depofit, which proves that nickel exifted in the combination in the ftate of a triple falt.

Fixed cauftic alkalies occafion no precipitation in this liquor; but they unake it refume its blue colour by decompofing the muriate of ammonia and laying bare its bafe, which then rediffolves the nickel.

The hydro-fulphurets formed in it an abundant black depofit; and this was the method employed for obtaining the nickel feparate. The hydro-fulphuret of this metal, calcined in a platina crucible, left a powder of a dark meadow-green colour, which had all the properties of oxide of nickel.

The iron contained in the ftones which have fallen from the heavens is therefore combined with fulphur and nickel; whence it appears very probable that thefe two fubftances, which always prefent themfelves in a quantity more or lefs confiderable in the analyfis of the whole ftones, arife from a fimilar combination, which it is impoffible, whatever care may be taken, to feparate exactly from the earthy parts.

The prefence of nickel and of fulphur in this iron explains why it is whiter, harder, and lefs ductile than common iron.

Though I did not afcertain very exactly the quantities of thefe fubftances in the iron, I think I may affert that they do not amount to more than five or fix per cent. In regard to the pyrites diffeminated here and there throughout thefe ftones, it is formed, as Mr. Howard fays, of iron, fulphur, and a fmall quantity of nickel; but I was not able to afcertain in what proportions thefe three fubftances are united, becaufe I had not a fufficien: quantity to fubject them to an exact analyfis.

It appears to refult from all the information obtained, and from teftimonies worthy of credit, ift, That maffes, fometimes of confiderable fize, have fallen to the furface of the earth: 2d, That thefe maffes penetrated with fire move in the atmofphere like inflamed balls, which throw light and heat, and to a great diftance: 3 , That they feem to have received a motion parallel to the horizon, though they rally defcribe a curve: 4 th, That they fall in a thate of fofinets or fufion like patte, as is attefted by their varnilhed furface; and the impreffions formed on them by the bodies which they meet with : $5^{\text {th }}$, That fome of them have fallen in England, Germany, Italy, France, and the Eaft Iudies: 6th, That all VOL. XV. No.60. A a the 
thefe ftones have a refemblance to each other by their phyfical characters and their chemical compofition.

What are the caufes which can produce ftones of this kind, and communicale to them fo rapid and fo fingular a motion? How comes it they are always penetrated with fire? Thefe are queftions for which at prefent it would be difficult to affign plaufible reafons.

But whatever thefe caufes may be, if multiple they muft be of the fame nature, fince all the ftones which have fallen in countries fo different have in every refpect a refemblance to each other.

Do they owe their origin to volcanoes? But where are thefe volcanoes? We are not yet acquainted with them; and ftones fimilar to thofe in queltion have never been found among the productions of any of the known volcanoes. Is the atmofphere the medium in which they are formed? But how can we conceive that fubftances fo heavy as earths and metals conld exift in fufficient quantity, and remain long enough fufpended in a fluid fo light as air? If we fuppofe that thefe bodies exifted in the atmofphere, whence did they originally come, and what means were fo powerful as to unite them, and to form of them maffes fo heavy and fo voluminous?

The opinion which makes them come from the moon, however extraordinary it may appear, is, perhaps, the leaft improbable; and if it be true, that no direct proofs can be given of this opinion, it is equally certain that no wellfounded reafoning can be oppofed to it.

The moft prudent courfe to be purfued in this ftate of things is freely to acknowledge, that we are entirely unacquainted with the origin of thefe ftones, and of the caufes which produced them.

LXIIT. Conjectures on the Stones wubicb bave fallen from the Atmoppere. By Euskius Salverte*.

$T_{\mathrm{H}}$

YIE antients never entertained any doubt in regard to what tiley obferved. As the natural fciences among them were cnly collections of facts, no theory compelled them to contradict their obfervations. We accufe them of often having feen without examining; but though we examine better ourfelves, we are often obliged to abjure our fcepticifm, and at length to fee what the ancients faw before us.

* From the Annizles de Cbimie, No. $1_{33}$. 